\title{
Conditions of Cost-Effectiveness for the Use of Real-Time Location Systems (RTLS) in Medical Facilities and the Benefits of Effective Implementation Process
}

\author{
DAMIAN BANAT \\ Department of Management, Faculty of Management and Production Engineering, \\ Lodz University of Technology \\ Human Capital Management Unit, Institute of Human Capital, \\ SGH Warsaw School of Economics
}

\begin{abstract}
Today, the healthcare system faces numerous challenges due to lack of visibility of resources and low utilisation, excessive rental as well as purchase of medical equipment. The article attempts to identify the possibilities of implementing a system of identification and location of assets in healthcare system institutions. This research presents market analysis in the context of available technological solutions. The implementation of the real-time location system (RTLS) would enable not only tracking of equipment and
\end{abstract}


inventory in medical facilities, but also increase visibility of inventory and manage the entire supply chain. The presentation of the proposed solution made it possible to assess costs, potential savings, and the implementation process. This article is a starting point for a discussion on the cost-effectiveness of using the RTLS in the healthcare system.

Keywords: healthcare system, Real-Time Location Systems (RTLS), asset tracking, Bluetooth Low Energy (BLE), change management

JEL Classification Code: O39

\section{Introduction}

Countless studies assume continuous instability in the healthcare environment, which is uncertain like never before in history, forced to confront increasing user demands and limited market resources (Hannagan, 2002; Acemoglu, 2009). Today's market is characterised by a high dynamics of change due to growing globalisation, increased competitive pressure, technological development and demands on the quality and effectiveness of services provided (Pan et al., 2008; Li et al., 2018). The dynamically changing market environment and technological development create new business opportunities, which are more and more often recognised in the healthcare sector. The need to understand the ongoing digital transition sets numerous challenges for both today's and tomorrow's management of healthcare institutions (Park \& Koh, 2017; Schuelke-Leech, 2018).

One of the challenges of modern institutions of the healthcare system is to maintain a growing quantity of resources and to estimate their availability. The increase in the amount of digital information and the need to continuously monitor processes and track assets results in an increasingly dynamic market for asset management and monitoring technologies (Technavio, 2017). Facility location systems for tracking and identifying the whereabouts of facilities are innovative solutions to support organisations and institutions where numerous assets and a significant number of employees pose a challenge to day-to-day operations. The precise, realtime location allows increasing efficiency and improving the functioning of the entire facility. These solutions help organisations achieve their goals by reducing inventory costs, managing inventory more efficiently and making more optimal use of existing equipment (Reyes et al., 2016). There are many systems that allow tracking company's resources, although each of them has different functionalities and uses diverse communication standards. Nevertheless, there is no overview of the available solutions and their value in the context of the healthcare system facilities, and no indication of the most optimal solution in a given sector, which 
justifies the topic. The purpose of this study is to identify existing solutions on the market that ensure comprehensive control of resources and to present their value in the context of the healthcare system. Another aim of the article is an attempt to indicate the possibility of implementing a system of identification and location of assets in medical institutions.

Today's facilities are often overcrowded with underused medical devices. Hospitals tend to acquire surplus medical equipment so that it is available to all employees at all times (Kamel Boulos \& Berry, 2012). It is worth noting that unused resources also generate costs, inter alia, related to depreciation, leasing or maintenance of equipment. Despite the apparent oversupply of medical equipment in medical facilities, it is not available at the right time, which creates a kind of dissonance. Studies conducted by GE indicate that on average nurses spend 21 minutes per shift looking for equipment they want to use at any given time to provide an appropriate service to their patients. At a time when limited staff resources in medical institutions are one of the greatest challenges in this sector, the described time losses have a huge impact on the quality of services provided (Horblyuk et al., 2012; Augur, 2017). Even the most innovative facilities face problems related to organisation and monitoring of resources. The study also suggests actions that healthcare system managers should undertake to reduce costs. The facilities have an opportunity to save hundreds of thousands of zlotys and redirect this money towards more basic hospital activities such as filling vacancies, improving infrastructure or expanding services. While the main objective of the healthcare system is to provide care to patients, it is also important to manage resources economically and minimise the costs of providing this care (Horblyuk et al., 2012).

\section{Object identification and location systems}

Object location systems to track and identify the location of items are innovative solutions to support factories, hospitals, administrative units and all other organisations where numerous assets and a significant number of employees pose a challenge to daily operations. Precise location allows increasing efficiency and automation of complex business processes. Choosing the right solution depends on the industry and the specific case of use (Dzeng et al., 2014; Huang et al., 2019).

The development of various technologies, initially allowing for object identification up to solutions offering precise locations in real time, is illustrated in Figure 1. 
Figure 1. Development of object identification and location systems

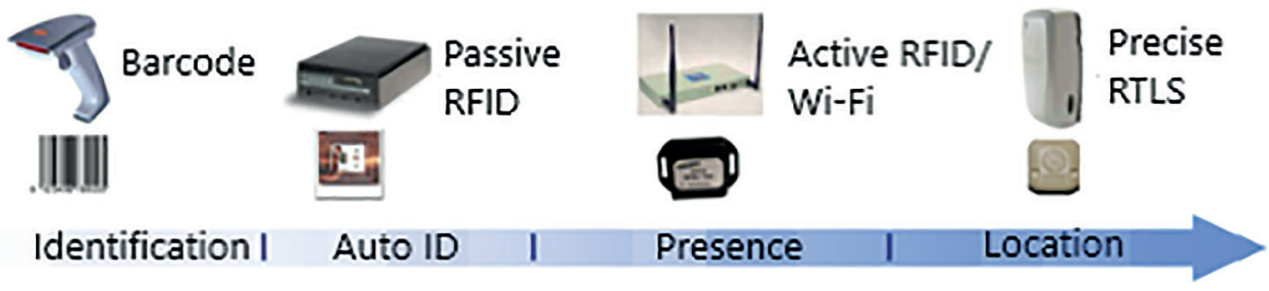

Source: own study based on Domalewski (2010).

\section{Barcode systems}

In the case of barcoding, object identification is only possible through direct contact and requires a line of sight to establish communication between the tag and the reader. It is a relatively old technology with numerous limitations. Unlike more advanced technologies, barcode scanning requires individual scanning, i.e. operator intervention is necessary. In addition, despite the lowest manufacturing costs, tags are not resistant to damage and have limited storage capacity. The drawbacks related to the use of this solution contributed to the need to develop systems for identifying and locating objects based on wireless technologies (McCathie, 2004).

\section{RFID systems}

Radio-frequency identification (RFID) systems use radio waves to transmit data wirelessly. On the market there are battery-free location tags, the so-called passive tags, which establish communication only in the presence of the reader, and tags equipped with batteries, the so-called active tags (Ni et al., 2004; Grier et al., 2007). The lack of power supply in passive RFID tags makes them cheap to produce and eliminates any concerns about battery life or charging. Active tags give their own signal to transmit the information stored in the tag. The internal power supply enables a longer communication range, and the readers do not need to transmit an electromagnetic field to power the markers (Davis, 2004; Roper et al., 2015). RFID technology has the advantages of durability, low cost and high data capacity. Systems using both active and passive RFID tags allow an object to be identified by information about the presence or absence of its tag. The system, therefore, only tracks the movements of objects or people. However, it does not allow one to locate the object in real time, which is the main limitation of this technology (Lee, 2014). 


\section{Real-Time Location Systems}

The systems enabling to determine the exact geographical location of an object in real time are the so-called Real Time Location Systems (RTLS). These are precise location systems that not only identify and track many different types of items, but also provide this information in real time through continuous communication.

RTLS are often confused with other asset tracking systems whose performance is relatively limited. The difference between the two is the continuous communication between the traced objects and the system. In traditional asset tracking systems, a tag interacts with the system only when it is read in a predetermined position. This means that object is located based on its last read position, not where it is currently located. Such a system may, for example, determine that an object is located in particular premises if the tag was identified when entering the room. However, it will not be able to locate precisely the place where a given object is located. Unlike traditional asset tracking systems, RTLS solutions provide accurate asset localisation through continuous and automatic communication between the tag and the reader (Clarinox, 2009).

All identified objects have a tag attached that can be located by RTLS (Wasp Barcode, 2019). By positioning the readers in fixed locations in a given environment, the location of tags is determined by analysing various aspects of communication between the readers and the tags. The most common techniques used in these calculations are: received signal strength indication (RSSI) or estimating the distance and angle between the tag and the reader. Complex algorithms allow the position of each marker to be determined continuously, i.e. in real time. Each RTLS tag has a unique serial number and is associated with a single object in the system database (Gaffney, 2008; Liard, 2012).

The information stored in the tags along with the current positioning of the object is then transferred to a related system for data visualisation and analysis. These interfaces most often provide real-time planning, execution and reporting functions, as well as a live view of the object, usually via Graphical User Interface. It is also possible to integrate data with Enterprise Resource Planning systems, while providing updates to key business processes such as delivery planning, warehouse management or order picking and execution. 


\section{Choice of technology}

The location and communication technologies used to operate RTLS are diverse. Their selection depends largely on the user's environment, system requirements, end use, compliance regulations and infrastructure. The choice of technology also significantly affects the accuracy of location information.

When implementing Wi-Fi based RTLS, it should be considered first and foremost that the tags are larger than other systems, consume significant amounts of power and are expensive. In addition, the performance of such a solution decreases in multistorey buildings or densely divided indoor environment, as signal reflections and network conditions can negatively affect transmitter readings (Masiukiewicz, 2014).

Infrared systems have the advantages of low energy consumption, low cost and compact size. Nevertheless, infrared radiation is sensitive to sunlight, so it is not suitable for rooms open to daylight. The reflection of light from floors and indoor monitors can also seem problematic. Once installed, the transmitters need to be continuously configured and adjusted to optimise performance and ensure certain accuracy, mainly due to the challenges of the light properties. Moreover, due to the required extensive infrastructure, infrared RTLS solutions are rarely used to upgrade existing buildings (Gaffney, 2008; Kamel Boulos \& Berry, 2012).

The system using ultra-wideband waves is the most accurate RTLS solution. Nevertheless, it requires a huge number of expensive readers. In fact, each tag needs $3-5$ readers to get an exact location. This is the type of technology most commonly used in warehouses to track each stock within a few centimetres. Nevertheless, medical facilities do not need such a precise location of resources, which makes the expense unjustified (Jimenez Ruiz \& Seco Granja, 2017).

The system using Bluetooth technology, based on the energy-saving communication standard BLE (Bluetooth Low Energy), is becoming increasingly important on the market. The advantages of this solution include relatively low costs, easy installation and precise location with an accuracy of 1 meter. The following benefit is that the solution can be supported by multiple operating systems and devices, including popular smartphones. The only problem with using systems based on the Bluetooth communication standard is maintenance. The battery located in the tag allows the system to function for 1 to 3 years. There are also industrial tags on the market, equipped with batteries, which ensure an extended period of operation up to 10 years (Bisio et al., 2016; Daniş \& Cemgil, 2017).

Finally, solutions based on the Bluetooth communication standard are selected for further analysis. The systems operate in real time and allow one not only to identify an object but also to locate it precisely. 


\section{Conditions for profitability}

The profitability analysis of investment in the implementation of the system includes the evaluation of costs, benefits, potential savings and ways to effectively implement the solution.

\section{Costs}

The system using Bluetooth technology has been selected from among the RTLS solutions available on the market as the most accurate in the context of healthcare facilities. The costs of the system are estimated for the needs of a hospital, where the purpose of the implemented system is to provide location of facilities on 2 floors of the hospital, including 40 independent rooms and 200 mobile devices. For the system to function properly, it is necessary to locate a signal receiver in each room and attach a marker that emits a Bluetooth signal to each localised object.

In the case of systems using older technologies, investment estimates could be based both on data from reports describing specific implementations and information presented by solution providers. For example, the investment cost of implementing a system based on RFID communication for a medium-sized hospital may range from PLN 760,000 to PLN 2,200,000, and in the case of smaller implementations, the system costs start from PLN 76,000 (Davis, 2004; Roper et al., 2015). Solutions based on Bluetooth technology are relatively new and a limited number of implementations on the market is an obstacle to making an accurate analysis of investment costs. The financial outlays that should be incurred in order to cover the investment costs were estimated on the basis of data presented by the solution providers. These are listed in Table 1.

Table 1. Estimated costs of the Bluetooth-enabled system - own study based on confidential data from one of the solution providers

\begin{tabular}{|l|c|c|c|}
\hline \multicolumn{1}{|c|}{ Calculation item } & Amount & Unit cost [PLN] & Total cost [PLN] \\
\hline Bluetooth marker & 200 & 80 & 16,000 \\
\hline Bluetooth receivers & 40 & 800 & 32,000 \\
\hline Monthly maintenance cost of equipment & 1 & 5 & 1,200 \\
\hline Annual maintenance cost of equipment & 12 & 60 & 14,400 \\
\hline TOTAL & - & - & 62,400 \\
\hline
\end{tabular}

Source: own study. 
A fully functional system based on Bluetooth technology requires the purchase of tags (the so-called Beacons) and readers that act as network gateways. As previously described, smartphones and other Bluetooth-enabled devices can also be used as part of the system infrastructure. The cost of maintenance includes equipment maintenance, including periodic battery replacement. The cost of middleware was deliberately omitted, as free tools and applications are available on the market (Pazowski, 2014; Wielki, 2016; Guth et al., 2018).

Estimated costs of the system ensuring location of facilities on 2 hospital floors, comprising 40 rooms and 200 mobile devices, estimate to PLN 62,400.

\section{Benefits of the system implementation}

First of all, it should be noted that hospitals tend to buy surplus medical devices because they have problems locating devices when they are needed. One of the sources says that the facilities purchase $10 \%$ to $20 \%$ of additional equipment (Kamel Boulos \& Berry, 2012). Another report shows that an average hospital cannot locate between $15 \%$ and $20 \%$ of its assets at any given time, thus, it purchases additional 20\%-30\% of its equipment (Roper et al., 2015). Nevertheless, the savings resulting from the limitation of the purchase of additional equipment are only one of the many identified advantages of implementing this solution in the context of medical institutions. The use of a system allowing for identification and location of facilities and personnel within the hospitals is also associated with the following benefits:

- limiting the time spent on finding the desired equipment, the use of which is required at a given time. Report prepared by GE (Horblyuk et al., 2012) indicates that the average time a nurse is looking for equipment is 21 minutes per shift. According to another report, this is $10 \%-30 \%$ of their total working time, which means that nurses spend even more of their time looking for tools and other medical supplies (Watfa, 2012). A study at the Bon Secours Health System in Richmond, Virginia, showed that staff spent $25 \%$ to $33 \%$ of their time looking for equipment (Glabman, 2004);

- limiting the rental of additional equipment to meet the total demand (Kamel Boulos \& Berry, 2012; Leantegra, 2017). Research carried out by Davis shows that American hospitals waste as much as USD 50,000 a month on unnecessary equipment rentals due to the lack of information about its availability (Davis, 2004);

- limiting the use of hazardous substances by unauthorised persons;

- preventing the theft or disappearance of expensive medical devices (Lee, 2014);

- minimising the time of searching for a lost patient in the hospital in order to conduct an examination, treatment or provide some information. In addition, 
during visits, visitors can use their own phones or tablets to locate the patient without interrupting the doctors or nurses to obtain this information (Yao et al., 2010).

The implementation of a system that allows the location of objects and personnel provides numerous financial and non-financial benefits. The implementation of the solution undoubtedly increases safety and quality of provided services, as well as improves the functioning of the entire medical facility.

\section{Savings}

Potential savings will be presented on the basis of available information on existing implementations of location systems in global markets and the savings achieved in the healthcare system. For approximately two years, the University of California Medical Center in San Diego has been using an RFID-based location system to track various assets on the Thornton campus in California. The hospital estimates that it has saved about USD 70,000 a year merely on identifying the location of intravenous pumps. The ability to easily locate the device has eliminated the need to hire additional pumps to meet the total needs of the facility (Lee, 2013). Another research report highlights that RFID technology is fully functional in the context of medical institutions, and for a hospital with 500 beds and 3000 mobile devices, savings in the first year after system implementation are on average over USD 1 million (Glabman, 2004; Efe \& Raghavan, 2009).

\section{Implementation process}

The implementation of a system based on the Bluetooth communication standard allowing for the identification and location of objects is not a complicated and costly operation at the time of effectively conducted gradual adaptation process. Hospitals should consider integrating the solution as a long-term process, rather than a single action to implement the system. Initial activities should be focused on solving one or two less complex problems, while retaining visions for further development of the system in order to use the solution in other areas of the facility. A systematic sequence of actions aimed at using functionality of the solution throughout the value chain allows for identification of sources of costs, profits and potential benefits (Roper et al., 2015).

Gradual implementation of the system has a number of advantages for the hospital, including lower risk of unsuccessful implementation and lower investment 
costs. Moreover, the value of the knowledge gained during the implementation of a single solution is invaluable. Hospitals are, to a greater or lesser extent, learning organisations, i.e. proficient in creating, acquiring and transferring knowledge and in modifying their activities in response to new knowledge and experience. The increased level of knowledge, based on own experience, significantly simplifies the justification of further investments in the discussed solution and ensures proper selection of the RTLS solution provider. Finally, the pilot system implementation facilitates scalability and further integration within the entire facility (Hitt et al., 2007; Radomska, 2014; Zeps \& Ribickis, 2015; Rey \& Bastons, 2017).

\section{Conclusion}

The healthcare system today faces numerous challenges due to the lack of resources visibility, as well as low utilisation and excessive rent and purchase of medical equipment, along with inefficient use of staff time. The current market requirements and limited resources of medical institutions make it necessary to consider implementing a system for identifying and locating assets.

The article is of a theoretical nature, the aim of which is to try to indicate the possibility of implementing a system of identification and location of objects in medical facilities. The study provides an overview of location systems using various barcode technologies, Wi-Fi, infrared, ultrasound, RFID and Bluetooth. Finally, based on the analysis of available solutions and the defined problem in the healthcare sector, a system based on the Bluetooth communication standard was selected as the optimal solution within the medical facility. The presented study also identified benefits related to the implementation of solutions ensuring comprehensive control of resources in the context of healthcare system institutions.

In addition to the theoretical contribution mentioned above, some practical managerial implications were found. On the basis of the analysis of available systems and indication of the most optimal solution in a given sector, the study should be used by healthcare system managers as a starting point for a discussion on the profitability of using RTLS in a given facility.

The implementation of an appropriate system in healthcare institutions is crucial to ensure that patients receive quality and timely treatment. The implementation of an object identification and location system may enable not only to track equipment in medical facilities, but also to increase inventory visibility, supply chain management, patient monitoring or document flow in a given facility. It also allows for planning equipment maintenance, creating inventory reports, reducing asset theft and detecting any shortage of stored funds in relation to real demand. Ultimately, the 
solutions presented enable to increase safety and reduce costs at the same time, without compromising the quality of patient care.

As technology development progresses, these solutions are becoming increasingly available and allow for their fully functional application in the healthcare sector. Sometimes even the slightest improvement in the way a given hospital operates can bring significant financial and non-financial benefits. Healthcare is a huge sector, so making general institutional changes is a long-term process (Heckmann et al., 2016). Nevertheless, it is precisely the developing technologies that are becoming more and more popular solution to the problems of medical facilities, as they enable to automate time-consuming processes and increase their efficiency.

\section{Further research directions}

It was concluded that, in the context of the presented potential implementation of the system in medical facilities, future research in areas related to cost-effectiveness is needed in order to estimate the period of return on investment. An important complementary element to the cost-effectiveness analysis would be to present the financial savings following the identified benefits. In addition, a comparative analysis of the costs of the systems offered by the different solution providers should also be presented before the start of a proper system implementation process. Ultimately, an assessment of costs, benefits and cost-effectiveness should be carried out for the specific use.

\section{References}

Acemoglu, D. (2009). Introduction to modern economic growth. Princeton: Princeton University Press.

Augur, H. (2017). 3 ways beacons are making IoT in healthcare better. Retrieved from: http://proximitystudio.com/3-uses-beacon-iot-in-healthcare-progress/ (accessed: 30.3.2019).

Bisio, I., Sciarrone, A., \& Zappatore, S. (2016). A new asset tracking architecture integrating RFID, Bluetooth Low Energy tags and ad hoc smartphone applications. Pervasive and Mobile Computing, 31, 79-93.

Clarinox (2009). Real time location systems. Clarinox.Com, 1-8.

Daniş, F.S., \& Cemgil, A.T. (2017). Model-based localization and tracking using bluetooth low-energy beacons. Sensors (Switzerland), 17(11), 1-23.

Davis, S. (2004). Tagging along. RFID helps hospitals track assets and people. Health Facilities Management, 17(12), 20-24. 
Domalewski, L. (2010). Precyzyjna lokalizacja w czasie rzeczywistym innowacja zwiększająca wydajność i automatyzację złożonych procesów biznesowych. Retrieved from: https:// docplayer.pl/9375447-Precyzyjna-lokalizacja-w-czasie-rzeczywistym-innowacjazwiekszajaca-wydajnosc-i-automatyzacje-zlosonych-procesow-biznesowych.html (accessed: 22.3.2019).

Dzeng, R.J., Lin, C.W., \& Hsiao, F.Y. (2014). Application of RFID tracking to the optimization of function-space assignment in buildings. Automation in Construction. Elsevier B.V., 40, 68-83.

Efe, K., \& Raghavan, V. (2009). Simulation modeling movable hospital assets managed with rfid sensors. Retrieved from: https://ieeexplore.ieee.org/document/5429662 (accessed: 30.3.2019).

Gaffney, B. (2008). Considerations and challenges in real time locating systems design. Dublin: DecaWave white paper. Retrieved from: http://www.decawave.com/sites/ default/files/resources/decawave_paper_on_rtls_0.pdf (accessed: 30.3.2019).

Glabman, M. (2004). Room for tracking. RFID technology finds the way. Retrieved from: https://pubmed.ncbi.nlm.nih.gov/15202205/ (accessed: 30.3.2019).

Grier, S., Marchini, M.F., \& Zimmerman, J. (2007). RFID asset tracking system. Retrieved from: https://edisciplinas.usp.br/pluginfile.php/4615596/mod_resource/content/6/ RFID_Asset_Tracking_System.pdf (accessed: 30.3.2019).

Guth, J., Breitenbücher, U., Falkenthal, M., Fremantle, P., Kopp, O., Leymann, F., \& Reinfurt, L. (2018). A detailed analysis of IoT platform architectures: concepts, similarities, and differences. Retrieved from: https://www.iaas.uni-stuttgart.de/ publications/INBOOK-2018-01-A-Detailed-Analysis-of-IoT-Platform-ArchitecturesConcepts-Similarities-and-Differences.pdf (accessed: 12.4.2019).

Hannagan, T. (2002). Managing strategic change. In: R. Pettinger (Ed.), Mastering strategic management. Palgrave, 181-201.

Heckmann, N., Steger, T., \& Dowling, M. (2016). Organizational capacity for change, change experience, and change project performance. Journal of Business Research, 69(2), 777-784.

Hitt, M.A., Ireland, D.R., \& Hoskisson, R.E. (2007). Strategic management. Mason: SouthWestern Cengage Learning, 104-136, 166-196.

Horblyuk, R. Kaneta, K., McMillen, G.L., Mullins, C., O’Brien, T.M., \& Roy, A. (2012). Out of control. How clinical asset proliferation and low utilization are draining healthcare budgets. GE Healthcare.

Huang, J., Wen, Z., Kong, L., Ge, L., Wu, M.-Y., \& Chen, G. (2019). Accelerate the classification statistics in RFID systems. Theoretical Computer Science, 788(8), 39-52.

Jimenez Ruiz, A.R., \& Seco Granja, F. (2017). Comparing ubisense, BeSpoon, and DecaWave UWB location systems: indoor performance analysis. IEEE Transactions on Instrumentation and Measurement, 66(8), 2106-2117.

Kamel Boulos, M.N., \& Berry, G. (2012). Real-time locating systems (RTLS) in healthcare. International Journal of Health Geographics, 11, 25. 
Leantegra (2017). RTLS-enabled asset and patient tracking for healthcare. Retrieved from: https://www.slideshare.net/Leantegra/rtlsenabled-asset-and-patient-tracking-forhealthcare (accessed: 14.4.2019).

Lee, I. (Ed.) (2013). Mobile services industries, technologies, and applications in the global economy. IGI Global.

Lee, I. (2014). RFID technology integration for business performance improvement. IGI Global. Li, M., Porter, A.L., \& Suominen, A. (2018). Insights into relationships between disruptive technology/innovation and emerging technology: A bibliometric perspective. Technological Forecasting and Social Change, 129, 285-296.

Liard, M. (2012). Understanding RTLS. What is it, how it's used \& what you need to know before deploying. Retrieved from: https://www.zebra.com/content/dam/zebra/whitepapers/en-us/understanding-rtls-vdc.pdf (accessed: 30.3.2019).

Masiukiewicz, A. (2014). Metody wyboru kanałów w sieciach 802.11. Przegląd rozwiązań. Zeszyty Naukowe Uczelni Vistula, 38, 38-49.

McCathie, L. (2004). The advantages and disadvantages of barcodes and radio frequency identification in supply chain management. Retrieved from: https://ro.uow.edu.au/ cgi/viewcontent.cgi?referer=https://www.google.com.sg/\&httpsredir=1\&article= 1009\&context=thesesinfo (accessed: 30.3.2019).

Ni, L.M., Liu, Y., Lau, Y.C., \& Patil, A.P. (2004). Indoor location sensing using active RFID. Kluwer Academic Publishers. Wireless Networks, 10(6), 701-710.

Pan, S.L., Pan, G., \& Devadoss, P.R. (2008). Managing emerging technology and organizational transformation: an acculturative analysis. Information and Management, 45(3), 153-163.

Park, K., \& Koh, J. (2017). Exploring the relationship between perceived pace of technology change and adoption resistance to convergence products. Elsevier Ltd. Computers in Human Behavior, 69, 142-150.

Pazowski, P. (2014). Ekonomiczne aspekty wdrożenia modelu cloud computing. Modern Management Review, 18 (XIX), 21(2), 81-95.

Radomska, J. (2014). Operational risk associated with the strategy implementation. Management, 18(2), 31-43.

Rey, C., \& Bastons, M. (2017). Three dimensions of effective mission implementation. Elsevier Ltd. Long Range Planning, 51(4), 580-585.

Reyes, P.M., Li, S., \& Visich, J.K. (2016). Determinants of RFID adoption stage and perceived benefits. North-Holland. European Journal of Operational Research, 254(3), 801-812.Roper, K.O., Sedehi, A., \& Ashuri, B. (2015). A cost-benefit case for RFID implementation in hospitals: adapting to industry reform. Emerald Group Publishing Limited. Facilities, 33(5/6), 367-388.

Schuelke-Leech, B.-A. (2018). A model for understanding the orders of magnitude of disruptive technologies. North-Holland. Technological Forecasting and Social Change, 129, 261-274. 
Technavio (2017). Global RTLS Market 2017-2021. Retrieved from: https://www. technavio.com/report/real-time-location-systems-market-industry-analysis (accessed: 21.4.2019).

Wasp Barcode (2019). Fixed Asset Tracking Software - Asset Management Systems. Retrieved from: https://www.waspbarcode.com/asset-tracking (accessed: 11.4.2019).

Watfa, M.K. (2012). E-healthcare systems and wireless communications: current and future challenges. Medical Information Science Reference.

Wielki, J. (2016). Internet rzeczy i jego wpływ na modele biznesowe współczesnych organizacji gospodarczych. Studia Ekonomiczne. Zeszyty Naukowe Uniwersytetu Ekonomicznego w Katowicach, 281. Retrieved from: https://www.ue.katowice.pl/fileadmin/user_upload/wydawnictwo/SE_Artyku\%C5\%82y_271_290/SE_281/17.pdf (accessed: 24.4.2019).

Yao, W., Chu, C.-H., \& Li, Z. (2010). The use of RFID in healthcare: benefits and barriers. In: 2010 IEEE international conference on RFID-technology and applications. IEEE, 128-134.

Zeps, A., \& Ribickis, L. (2015). Strategy development and implementation - process and factors influencing the result: case study of Latvian Organizations. Elsevier B.V. Procedia - Social and Behavioral Sciences, 213, 931-937.

\section{Damian Banat}

A graduate of master's degree studies in Management at SGH Warsaw School of Economics with two specialisations: Human Resources Management and Project Management. A graduate of both engineering and master's studies at the Lodz University of Technology, and currently a doctoral student at the Interdisciplinary Doctoral School. He also completed a master's degree in International Business Management at the INSEEC Business School in Paris. For over 5 years he has been working in the IT environment as Senior Consultant and Business Development Manager, responsible for supporting companies from various industries in digitisation processes. Author of many expert articles on industry portals in the area of Industry 4.0.

email address: damian.banat@dokt.p.lodz.pl

ORCID: 0000-0002-0175-6542 